\title{
Assessing the degradation of vegetation of arid zones using FAO- UNIP model (case study: Kashan zone)
}

\author{
Hamid Alipur $^{1} \cdot$ Mohamad Zare $^{1} \cdot$ Saeed Shojaei $^{1}$
}

Received: 29 October 2016/ Accepted: 2 November 2016/Published online: 9 November 2016

(C) Springer International Publishing Switzerland 2016

\begin{abstract}
The process of desertification has a high intensity in developing countries as well as countries possessing high potential of desertification Therefore, particularly for those countries, it is necessary to combat against this phenomenon of desertification. Desertification is the diminution of ecological and biological potential of land occurring naturally or due to human activities. Identifying the factors leading to desertification and assessing their processing is critically important for ecosystem management of wild and arid zones. The main objective of this study is to evaluate the degradation of vegetation in Kashan (1984) located in the East of the catchment of Namak Lake, using FAO-UNEP model. For this purpose, the degradation of vegetation was evaluated in terms of the status quo by measuring the percentage of the permanent vegetation, the quality of range and forage production yield as well as natural talent using the maps of thermal and moisture regimes of the soil and the map of lana capability. The results show that about $74 \%$ of the study area is grouped at very severe degradation class in terms of the status quo and about $84 \%$ of the area is categorized at severe and very severe degradation class in terms of natural talent. Overall results indicate the appropriateness of FAO-UNIP model for evaluating the degradation of vegetation in terms of status quo and natural talent, according to the extant realities of the arid zone.
\end{abstract}

Saeed Shojaei

s_shojaei@ut.ac.ir

1 Department of Management the Arid and Desert Regions, College of Natural Resources and Desert Yazd University, Yazd, Iran
Keywords Desertification aspects - Land degradation . Quality of range - Geographic information system (GIS) . Kashan

\section{Introduction}

More than $80 \%$ of Iran is located in the realm of arid and semi-arid to dry sub-humid climate. As a result, due to climate conditions and natural features governing it, much of ecosystems were very sensitive and fragile against improper operation practices and are potentially or practically exposed to desertification. Desertification is propounded as one of the most obvious aspect of natural resources degradation in the world. Over the past decades, numerous global efforts have been accomplished to tackle and regulate this phenomenon. Desertification is of process reducing territories 'efficiency through increasing speed in trans-regional scale as well as increasing the qualitative and quantitative range of environmental pollution (Masoudi 2010). The interim evaluation model and mapping of desertification was first complied and introduced by the two institutions affiliated to the United Nations (i.e. Agricultural Foodstuffs Organization and United Nations Environment Program) (Darvish 1999; FAO and UNEP 1984). Fashion designers have been nominated and introduced seven natural processes as the identification of desertification process including: decaying vegetation, water erosion, wind erosion, salinity (salting soil), reducing soil organic matter, crust formation and compactness of the soil, and accumulation of toxins for plants and animals in the soil. They also stated that, among the seven processes mentioned above, the first four processes play a significant and determinant role and the next three processes are considered as the secondary factors of desertification 
(Meshkat 1998). This is due to the span of the effects of four mentioned processes as well as their more effective role in reducing land efficiency. In addition to the seven natural processes mentioned above, two other processes of human origin are also presented in this method including; livestock pressure on the environment and pressure of population on the environment. The above processes have also evaluated from three perspectives such as the current situation, natural talent and desertification velocity. In this paper, the process of the destruction of vegetation is evaluated in terms of the current situation and natural talent. In addition to FAO and UNEP, many scientists and researchers have provided some methods regarding the qualitative and quantitative assessment of the desert. In contrast to the view of FAO and UNEP highlighted the role of human pressures on evaluating land desertification process; Ahmadi (1997) has just prominent three criteria in the development and formation of Iran's deserts and isolating them from each other and has been introduced as follows: ecological criteria, territorial criteria (geological, geomorphology of land and soil), vegetation criteriaecology, while Kordavani has found this issue easier and still considered ecological criteria as a single formation factor and manifest characteristic of the desert. This is while others; including Siddiqui (1991), Servati (1997) and Khalili (1999) explicitly reject a one-dimensional look toward this phenomenon. Considering the viewpoint, Ekhtesasi and Mohajeri (1997) have holistically tried to provide a more realistic assessment of desertification process. They introduced a method based on the needs of the study and environmental, social and economic structures governing the deserts of Iran, which has been registered with the abbreviated name (D.I.C). In this model, eight efficacious indicators were introduced for desertification including: three environmental factors (climate, geomorphology of the land, and the quality and quantity of soil and water resources), three human factors (degradation of plant resources, degradation of water resources, and degradation of soil and land resources) and finally, two indicators of the intensity of soil erosion and restoration power. It can be noted to other researches such as Babaev et al. (1993) who presented the new model to produce maps of effective functions in the process of land degradation at a scale of $1: 2,500,000$. The space of their study area is two million $\mathrm{km}^{2}$ and the Aral Lake was located in it where they have been assessed the contribution of the process of water logging as a negligible and low-impact value for the occurrence and escalation of desertification process. Abbas Abadi (1999) also tried to determine the contribution of each desertification factors through the study and quantitative evaluation of desertification process in the plateau "Aq Qala". The results showed that the factor of land water logging play the far more decisive role in forming and intensifying reductive processes of land efficiency. Although the latter factor is leading to reveal and exacerbate of another factor of the main indicators of desertification, that is, land Stalinization. Besides, among natural factors, the role of geomorphologic factor of the land was more prominent than others and, ultimately, among human indicators, the indiscriminate exploitation of natural resources has, particularly overgrazing, been introduced as a desertification factor. Meshkat (2006) sketched the map of the decadence of vegetation, wind erosion and saline lands for a part of the Yazd plain. $\mathrm{He}$ concluded that the degree of destruction of vegetation has already determined as severe to very severe, and salinity expanse from moderate to severe and the rate of wind erosion is as negligible to moderate. Natural talent of these three processes is estimated as very severe, moderate to severe and moderate to severe. The aim of this study is to destroy the vegetation using FAO and UNEP in the area of Kashan.

\section{Materials and methods}

\section{The characteristics of the study area}

The studied sub-basin is located in the east of the catchment "Namak Lake". This (restricted) area has surrounded the half of "Qom", more than $80 \%$ of the space of "Kashan, Aran and Bidgol, and a part of Natanz and Garmsar". The maximum height of this area is $3588 \mathrm{~m}$ above sea level (Karkas Mountain in southern highlands) and a minimum height of Namak Lake is $800 \mathrm{~m}$ above sea level. The study area covers about 1,600,000 hectares. A number of rivers with low catchment area are originated from the northern slopes of Mount "Karkas" and flow towards the plateau "Kashan" and Namak Lake. Due to the severe shortage of rainfall in these highlands, the rivers often have very little and except for exceptional cases, all the water is used for irrigation and penetrating into underground water reservoir in the upstream and foothills. Due to the wide altitudinal range, this area has various climates. According to meteorological information of synoptic stations in Kashan, the average annual rainfall is $137 \mathrm{~mm}$, the average annual temperature is $18 / 9{ }^{\circ} \mathrm{C}$ and the minimum and maximum annual evaporation are 2100 and $3162 \mathrm{~mm}$, respectively. Based on Demarton method (with a stiffness coefficient of 4/7), the regional climate is hyper-aired. Namak Lake is a large and wide pan of a scale, which considered as a terminal for a large number of surface and underground flows in the northwest of central great catchment of Iran. This massive evaporation zone is located in the northeast of Kashan, south of Tehran, and east of Qom. 


\section{Methodology}

In this study, the destruction of vegetation was surveyed in terms of the status quo and natural talent on the basis of the modified model of FAO and UNEP in the study area. The model is evaluated in the form of explanation of National Plan Services and presented the mapping of desertification using FAO and UNEP in the catchment of Namak Lake (Darvish 2007). The decadence of vegetation was evaluated and discriminated for each vegetation type in terms of the status quo through the measurement of the percentage of permanent vegetation, the quality of pasture and the rate of forage production ( $\mathrm{kg}$ per hectare), based on the Table 1 .

According to the latent concepts of thermal and moisture regimes (Ammari 1991) as well as the information obtained from the map of land capability, natural talent or in other words the degree of inherent territory vulnerability were calculated from the perspective of the destruction of vegetation. The set of units and the types of existing lands was first introduced in the basin "Kashan" and then after consulting with the experts, it is being carried out to classify and weight them according to the features of the soil texture and depth, limitations of salinity and alkalinity (Malakoti and Homayi 1994) and erosion based on Table 2.

The classification and weighting of soil moisture regime has been made based on Tables 3 and 4 and after consulting with experts.

The final plan has been made from the geometric mean of three mentioned maps using the software ILWIS, based on Table 5. It should be noted that all demographer believe that the best blending mode of indicators together is the use of geometric mean between them; a belief that the researchers of Europe Commission have the seal of approval (Kosmas et al. 1999).

\section{Results}

Figures 1, 2 and 3 show the maps of the percentage of canopy cover, the quality of range and forage production, respectively, based on the above models divided into four classes. Using the geometric mean of these three maps in ILWIS, map of vegetation degradation process was drawn in terms of the current situation (Fig. 4). The area and percentage of each class is shown in Table 6. Considering the results obtained from these figures and tables in the study area, in view of the current situation, the most area and the percentage of degradation of vegetation is relating to the most severe class with 1,164,256 hectares and $95 / 73 \%$ and the lowest area is connected to the negligible intensity class.

Figure 5 shows classification and zoning of types and units on the map of land capability. Figure 6 shows classification and zoning soil moisture regimes and Fig. 7 shows classification and zoning soil thermal regimes. Figure 8 shows the destruction of vegetation regarding the natural talent that comes through geometric mean of the above triple indices. In Table 7, the area and percentage of each class is given to the total basin area. The results show that the most severe class with 703,202 hectares and 44/66\% are allocated the most area and percentage of the degradation of vegetation in the study area particularly in terms of the natural talent. And also the class of negligible intensity has the lowest area and percentage.

Table 1 The classification of the destruction of vegetation in terms of the current status

\begin{tabular}{|c|c|c|c|c|}
\hline $\begin{array}{l}\text { The degree and weight of } \\
\text { desertification evaluation } \\
\text { indices }\end{array}$ & Negligible (2/5) & Average (5) & Severe $(7 / 5)$ & Very severe (10) \\
\hline $\begin{array}{l}\text { 1. The crest of permanent } \\
\text { vegetation }\end{array}$ & $>30$ & $20-30$ & $10-20$ & $<10$ \\
\hline 2. The quality of pasture & $\begin{array}{l}\text { Desirable species were } \\
\text { linked with average } \\
\text { species and a number of } \\
\text { valueless species is less } \\
\text { than } 25 \%\end{array}$ & $\begin{array}{l}\text { Average species are can } \\
\text { be solitarily or in } \\
\text { combination with } \\
\text { valueless species } \\
\text { formed } 25-50 \% \text { of } \\
\text { dominant plant } \\
\text { composition }\end{array}$ & $\begin{array}{l}\text { Valueless species are } \\
\text { formed } 50-75 \% \text { of } \\
\text { dominant plant } \\
\text { composition }\end{array}$ & $\begin{array}{l}\text { Valueless species (invasive) } \\
\text { are formed more than } \\
75 \% \text { of the dominant } \\
\text { coverage }\end{array}$ \\
\hline $\begin{array}{l}\text { 3. The production of } \\
\text { rangeland forage ( } \mathrm{kg} \\
\text { per hectare) }\end{array}$ & $>200$ & $100-200$ & $50-100$ & $<50$ \\
\hline
\end{tabular}


Table 2 The circumstances (models) of classifying and weighting units concerned with the types of land capability map

\begin{tabular}{lll}
\hline Weight & Class & Land units \\
\hline 1 & Negligible (1) & $4.1,4.2,4.5$ \\
$1 / 33$ & Average (2) & $2.5,4.6,4.7,7.1,8.1,8.2,9.2,9.3, \mathrm{C} 2, \mathrm{C} 3, \mathrm{X} 3$ \\
$1 / 66$ & Severe (3) & $2.2,2.3,3.1,3.2,3.3,3.5,7.2,7.5,9.1, \mathrm{C} 1$ \\
2 & Very severe (4) & $1.1,1.2,1.3,1.4,2.1,2.4,3.4,4.3,4.4,6.1,6.2,6.3,6.4,6.5,7.3,7.4, \mathrm{X} 1, \mathrm{X} 2$ \\
\hline
\end{tabular}

Table 3 The classification and weighting soil moisture regimes

\begin{tabular}{llll}
\hline Moisture regime & Signal & Class & Weight \\
\hline Yudik & $\mathrm{U}$ & Negligible (1) & 1 \\
Zerik and Yustik & $\mathrm{X}$ and T & Average (2) & $1 / 33$ \\
Weak Aridik (Aridik and Zerik) & AW & Severe (3) & $1 / 66$ \\
Aridik index and hyper-dry Aridic & At and Ae & Very severe (4) & 2 \\
\hline
\end{tabular}

Table 4 The circumstances of classifying and weighting soil thermal regimes

\begin{tabular}{lll}
\hline Thermal regime & Class & Weight \\
\hline Mezik & Eligible (1) & 1 \\
Thermic & Average (2) & $1 / 33$ \\
Frijid & Severe (3) & $1 / 66$ \\
Hyper-thermic & Very severe (4) & 2 \\
\hline
\end{tabular}

Table 5 The weight range of inherent vulnerability classes of the range-land

\begin{tabular}{ll}
\hline Class & Range \\
\hline Eligible (1) & $1-1 / 25$ \\
Average (2) & $1 / 25-1 / 5$ \\
Severe (3) & $1 / 5-1 / 75$ \\
Very severe (4) & $1 / 75-2$ \\
\hline
\end{tabular}

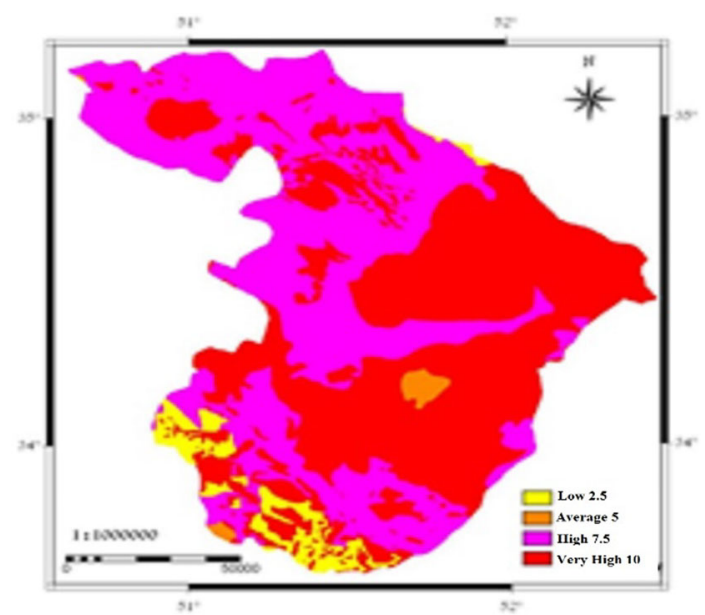

Fig. 1 The status of permanent vegetation canopy regarding the current status

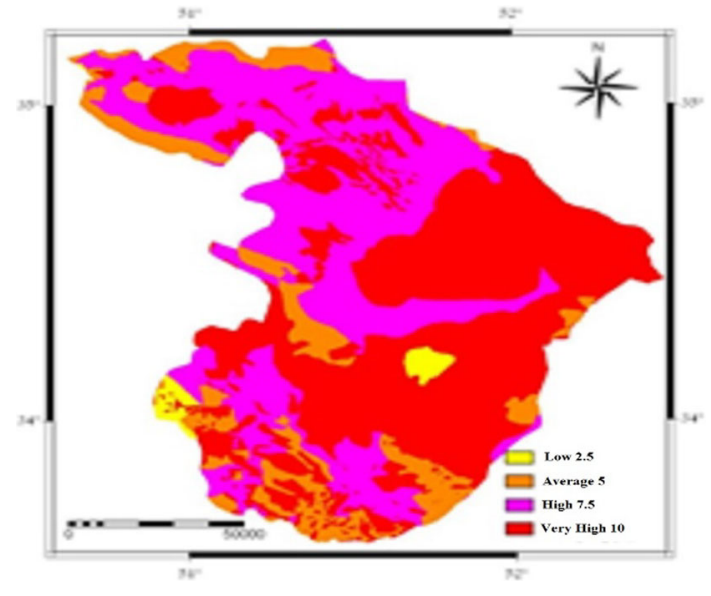

Fig. 2 The quality of range regarding the current status

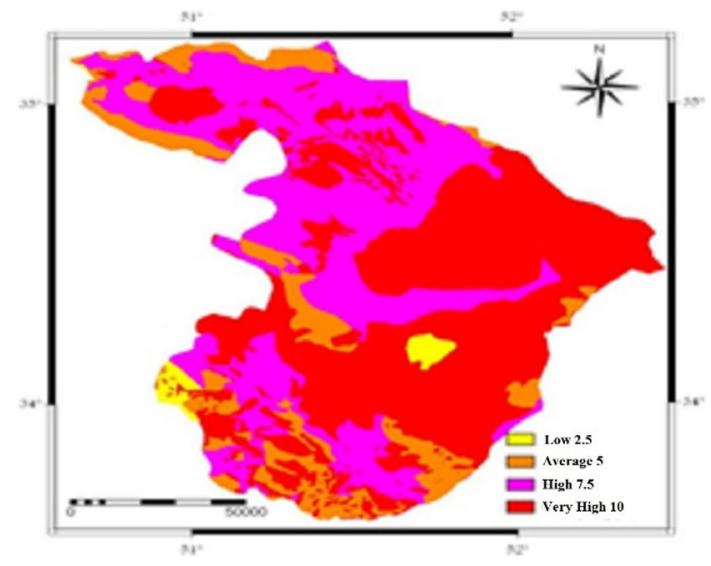

Fig. 3 Production regarding the current status

\section{Discussion and conclusion}

We should consider two questions in discussing combat against the expansion of desertification: a regional status quo and natural potential and talent of the region. The first 


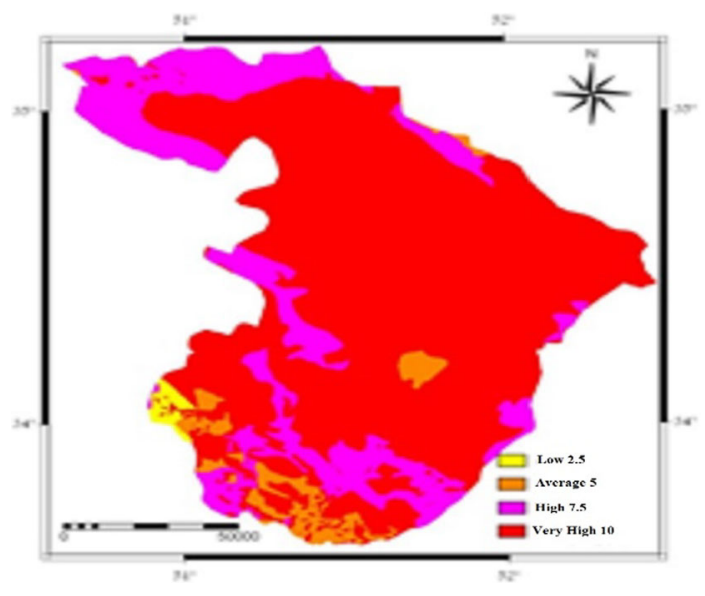

Fig. 4 The decay of vegetation regarding the current status

Table 6 The area and percentage of the classes of vegetation destruction map in terms of the current situation

\begin{tabular}{lllll}
\hline Intensity & Negligible & Average & Severe & Very severe \\
\hline Area (ha) & 12,364 & 66,120 & 331,600 & $1,164,256$ \\
Percentage (\%) & $0 / 78$ & $4 / 2$ & $21 / 07$ & $73 / 95$ \\
\hline
\end{tabular}

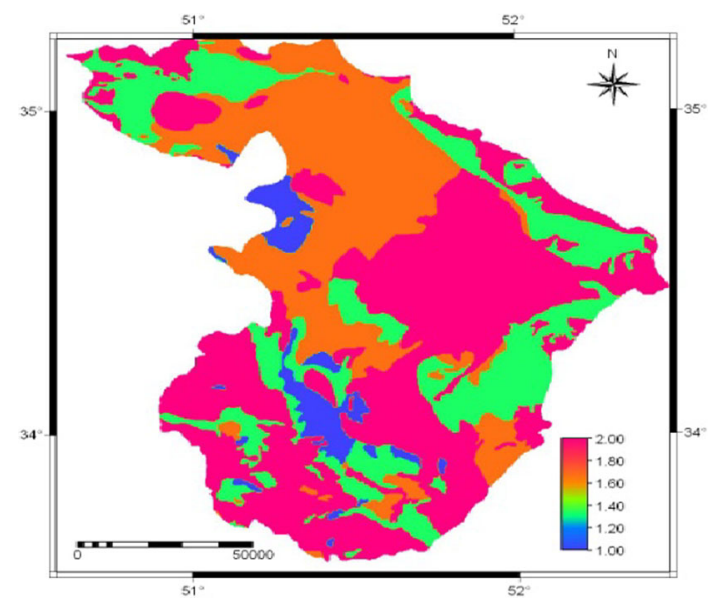

Fig. 5 Regional land capability

case refers to the environmental and human performance. The resultant of the two forces is a situation that we are witnessing now. So our great responsibility is to reform the type of management and operation. Our strategies should be in such a way that at least minimizes the pressure arising from human performance and try to reduce environmental stresses as much as possible. Regarding regional natural talent, we are dealing with environmental factors as it can be seen from the variables involved in the process of assessment. These factors are influenced by rainfall, temperature and soil capability as the activities' bed. The

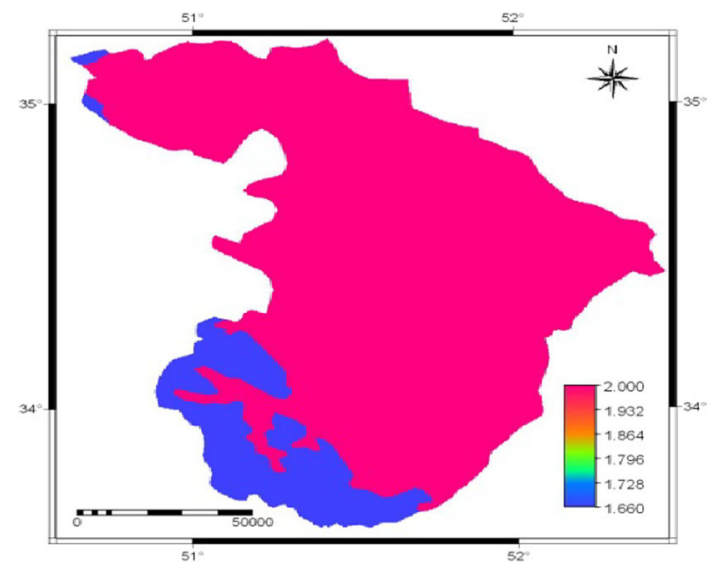

Fig. 6 Regional soil moisture regime

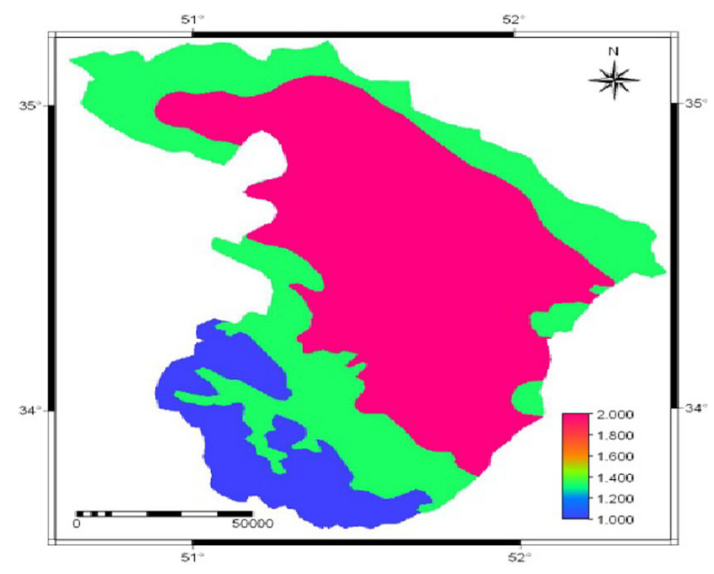

Fig. 7 Regional soil thermal regimes

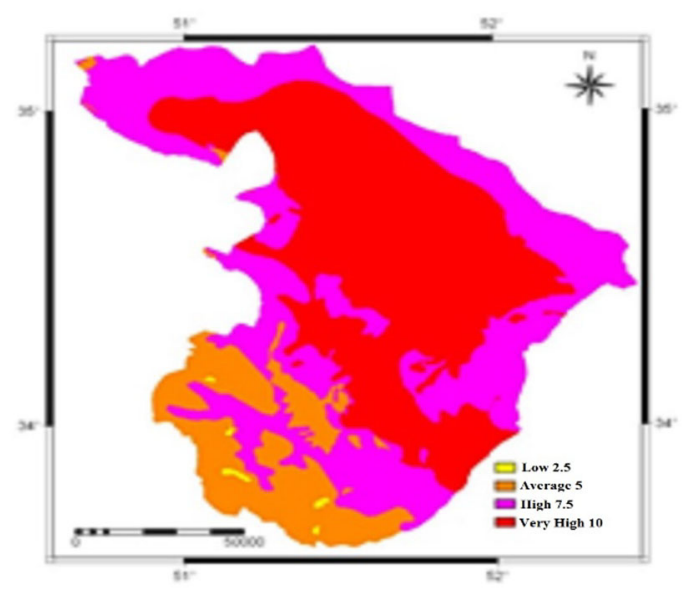

Fig. 8 The decay of vegetation in terms of the natural talent

results show that there is no favorable condition in the study area in terms of the status quo. Since more than $75 \%$ of the region is located at the class of very severe destruction and only $0 / 75 \%$ is relating to the desirable conditions and negligible class. So the first thing the result 
Table 7 The area of classes of the destruction of vegetation map in terms of natural talent (hectare)

\begin{tabular}{lllll}
\hline Intensity & Negligible & Average & Severe & Very severe \\
\hline Area (ha) & 11,106 & 238,193 & 631,834 & 703,202 \\
Percentage (\%) & $0 / 71$ & $15 / 13$ & $39 / 50$ & $44 / 66$ \\
\hline
\end{tabular}

reminds us is the problem of inappropriateness of regional utilization management from past to the present. The type and intensity of exploitation of vegetation must be revised before any resuscitation operation since this type of operation makes any recovery operation fails. According to the study and examination of the map of regional conventional systems that had formed a part of the research as the pressure of livestock on the environment, considering the accuracy of statistics on the number of livestock in the conventional systems, more than $60 \%$ of the region is under the extreme pressure and very severe extensive grazing (Abtahi 2008). So in discussing the revival of the region, we should apply the new pasturage before using heavy expenditure for range-planting and a variety of models to combat against land degradation. In the second phase of reclamation activities, we should take a look at the regional natural talent and potential. Because in terms of being the largest regional area in arid and hyper-arid climate, more than $85 \%$ of the basin is located at natural inappropriate conditions in terms of soil, rainfall and temperature. In general, the models used to assess the decay of vegetation in terms of the status quo and natural talent is appropriate according to the extant facts. And it is recommended to apply these models for other areas of the country where the climate is arid and semi-arid.

\section{References}

Abbas Abadi MR (1999) Quantitative assessment of desertification in the plateau "Aq Qala" in Gemishan to provide a regional model, master's thesis of desertification. Tehran University, p 250

Abtahi SM (2008) Assessing and mapping of desertification using FAO and UNEP models in the catchment "Kashan", the final report of the project. The Research Institute of Forests and Rangelands, p 158

Ahmadi H (1997) "Recognition criteria of Iranian desert", the second national conference on desertification and different methods of desertification in Kerman. Research Institute of Forests and Rangelands, publication 175

Ammari P (1991) Appeals on the map of thermal and moisture regimes of Iranian soil. Master Thesis of Pedology, Faculty of Agriculture, Tehran University, p 106

Babaev AG, Kharin NG, Orlovsky NS (1993) Assessment and mapping of desertification processes a methodological guide. Academy of sciences of Turkmenistan, Desert Research Institute, Ashgabad, pp 20-45

Darvish M (1999) Managerial feasibility in the use of desertification mapping model using FAO and UNEP in Iran. Masters of Degree of Environment Management, Science and Research Campus, p 274

Darvish M (2007) description of national plan services of assessment and desertification mapping using modified FAO and UNEP in the catchment of Namak Lake. Research Institute of Forests and Rangelands, p 27

Ekhtesasi MR, Mohajeri S (1997) Classification method and the intensity of land desertification in Iran. In: Proceedings of the second national conference and various methods of desertification in Kerman. Research Institute of Forests and Rangelands, publication 175

FAO, UNEP (1984) Provisional methodology for assessment and mapping of desertification. FAO, Rome, p 85

Khalili A (1999) Dry weather with $500 \mathrm{~mm}$ of rainfall. Hamshahri Newspaper, No. 1869

Kosmas C, Gerontidis St, Detsis V, Zafiriou Th, Marathianou M (1999) Application of the MEDALUS methodology for defining ESAs in the Lesvos Island, EU

Malakoti MJ, Homayi M (1994) "Fertility of soils of arid regions", problems and solutions. Modares University Press, Tehran, p 550

Masoudi R (2010) The initial warning system of desertification based on two factors of water and climate (case study: Kashan Plain). Master Thesis of Desertification, Faculty of Natural resources, Tehran University, p 187

Meshkat MA (1998) Temporary method for assessing and mapping of desertification. Publishing Research Institute of Forests and Rangelands, p 104

Meshkat MA (2006) Sketching the decay of vegetation, wind erosion, and saline lands for a part of Ardakan plain in Yazd, Research Quarterly of Iranian desert and range

Servati MR (1997) The wilderness and its geomorphology. In: Proceedings of the second national conference and various methods of desertification in Kerman, Research Institute of Forests and Rangelands, publication 175

Siddiqui M (1991) Landforms of arid area (translation), publication of Astan Quds Razavi, p 633 